\title{
Left atrial size and risk for all-cause mortality and ischemic stroke
}

\author{
Alberto Bouzas-Mosquera MD, Francisco J. Broullón MS, Nemesio Álvarez-García MD, Elizabet Méndez MD, \\ Jesús Peteiro MD PhD, Teresa Gándara-Sambade MSc, Oscar Prada MD, Víctor X. Mosquera MD, \\ Alfonso Castro-Beiras MD PhD
}

See related commentary by Goldstein at www.cmaj.ca/lookup/doi/10.1503/cmaj.110617

\begin{abstract}
Background: Limited data are available on the relation between left atrial size and outcome among patients referred for clinically indicated echocardiograms. Our aim was to assess the association of left atrial size with all-cause mortality and ischemic stroke in a large cohort of patients referred for echocardiography.
\end{abstract}

Methods: Left atrial diameter was measured in 52639 patients aged 18 years or older (mean age 61.8 [standard deviation (SD) 16.3] years; $52.9 \%$ men) who underwent a first transthoracic echocardiogram for clinical reasons at our institution between April 1990 and March 2008. The outcomes were all-cause mortality and nonfatal ischemic stroke.

Results: Based on the criteria of the American Society of Echocardiography, $50.4 \%$ of the patients had no left atrial enlargement, whereas $24.5 \%$ had mild, $13.3 \%$ had moderate and $11.7 \%$ had severe left atrial enlargement. Over a mean follow-up period of 5.5
(SD 4.1) years, 12527 patients died, and 2314 patients had a nonfatal ischemic stroke. Cumulative 10-year survival was $73.7 \%$ among patients with normal left atrial size, $62.5 \%$ among those with mild enlargement, $54.8 \%$ among those with moderate enlargement and $45 \%$ among those with severe enlargement $(p<0.001)$. After adjustment in multivariable Cox proportional hazard analysis, left atrial diameter remained a predictor of all-cause mortality in both sexes (hazard ratio [HR] per $1-\mathrm{cm}$ increment in left atrial size $1.17,95 \%$ confidence interval $[\mathrm{Cl}] 1.12-$ $1.22, p<0.001$ in women, and HR 1.09, 95\% Cl 1.05-1.13, $p<0.001$ in men) and of ischemic stroke in women (HR 1.25, 95\% Cl 1.14-1.37, $p<0.001$ ).

Interpretation: Left atrial diameter has a graded and independent association with allcause mortality in both sexes and with ischemic stroke in women.
$\mathrm{T}$ he left atrium plays a major role in cardiac physiology by collecting blood during systole and modulating left ventricular filling during diastole. ${ }^{1}$ Left ventricular diastolic dysfunction or mitral valve disease may lead to left atrial pressure or volume overload which, if chronically maintained, may result in left atrial remodeling and enlargement. ${ }^{2}$ As a marker of left ventricular diastolic dysfunction ${ }^{3}$ or increased filling volumes, left atrial size may provide important prognostic information. In this regard, left atrial enlargement has been related to higher risk of atrial fibrillation ${ }^{4-7}$ and cardiovascular events..$^{8-13}$ Our aim was to assess the association of left atrial size with all-cause mortality and ischemic stroke in a large cohort of patients referred for echocardiography.

\section{Methods}

\section{Patients}

Between Apr. 4, 1990, and Mar. 11, 2008, 116114 transthoracic echocardiograms were performed in our institution and were entered in a prospectively collected database. For each patient, the first comprehensive transthoracic echocardiogram was selected, leaving a sample of 54513 patients. We further excluded 863 patients who were younger than 18 years, 128 patients who had a prior history of cardiac transplantation and 883 patients for whom no followup data was available. Thus, 52639 patients were finally included. The study was approved by the local research ethics committee (Comité Ético de Investigación Clínica de Galicia), which waived the requirement for patient consent.
Competing interests: None declared.

This article has been peer reviewed.

Correspondence to: Dr. Alberto BouzasMosquera, alberto.bouzas .mosquera@sergas.es

CMAJ 2011. DOI:10.1503 /cmaj.091688 


\section{Clinical data}

Demographic, clinical and echocardiographic data were entered in our database at the time of the echocardiograms. The study was completed using linked clinical and administrative databases as well as electronic medical records through the Department of Information Technology of our institution. Data sources were linked using unique identifiers.

Diabetes mellitus was defined as a prior fasting serum glucose level of $126 \mathrm{mg} / \mathrm{dL}$ or higher or a nonfasting glucose level of $200 \mathrm{mg} / \mathrm{dL}$ or higher, abstracted from comprehensive laboratory databases. Hypercholesterolemia was defined as a total cholesterol level of $220 \mathrm{mg} / \mathrm{dL}$ or higher in any prior laboratory test. Hypertension was defined as either blood pressure higher than $140 / 90$ or a previously established diagnosis. A history of atrial fibrillation was defined as atrial fibrillation recorded at the time of the echocardiogram or any previously known episode of atrial fibrillation. A history of mitral valve intervention was defined as prior mitral valve replacement or repair or prior percutaneous or surgical mitral commissurotomy. Chronic kidney disease was defined as an estimated glomerular filtration rate less than $60 \mathrm{~mL} / \mathrm{min} / 1.73 \mathrm{~m}^{2}$ using the abbreviated Modification of Diet in Renal Disease Study equation in at least two prior observations more than 90 days apart. ${ }^{14}$

\section{Echocardiographic data}

Echocardiograms were performed in the left lateral decubitus position using standard imaging planes, according to the recommendations of the American Society of Echocardiography..$^{15}$ Left atrial diameter was measured using M-mode or two-dimensional echocardiography, from the posterior aortic wall to the posterior left atrial wall, in the parasternal long-axis view at the end-ventricular systole ${ }^{16}$ (i.e., just before the mitral valve opening). Left atrial diameter was categorized as a sexspecific variable, such that left atrial enlargement was defined as a left atrial diameter of $4.1 \mathrm{~cm}$ or greater in men or $3.9 \mathrm{~cm}$ or greater in women; a left atrial diameter below these values defined normal left atrial size. Left atrial enlargement was further classified as mild (left atrial diameter 4.1$4.6 \mathrm{~cm}$ in men or $3.9-4.2 \mathrm{~cm}$ in women), moderate $(4.7-5.1 \mathrm{~cm}$ in men or $4.3-4.6 \mathrm{~cm}$ in women) or severe ( $\geq 5.2 \mathrm{~cm}$ in men or $\geq 4.7 \mathrm{~cm}$ in women) in accordance with the recommendations of the American Society of Echocardiography. ${ }^{16}$ The intraobserver and interobserver variability for the classification of left atrial size into these four categories was assessed by two independent observers (A.B-M. and E.M.) in a subset of 40 randomly selected patients. The intraobserver agreement was $87.2 \%(\kappa=0.82$, standard deviation [SD]
$0.07)$, and the interobserver agreement was $84.6 \%$ $(\kappa=0.79$, SD 0.08).

Left ventricular ejection fraction was estimated using the Teichholz formula or the Simpson rule. Left ventricular systolic dysfunction was defined as left ventricular ejection fraction $<55 \% .{ }^{16}$ Ventricular septal thickness, left ventricular posterior wall thickness, and enddiastolic and end-systolic left ventricular diameters were also measured. Left ventricular enlargement was defined as an end-diastolic left ventricular diameter of $60 \mathrm{~mm}$ or greater in men or $54 \mathrm{~mm}$ or greater in women..$^{16}$ Left ventricular mass was calculated according to the formula by Deveraux and colleagues. ${ }^{17}$ The degree of mitral regurgitation was determined semiquantitatively based on parameters such as regurgitant jet area, jet profile in continuous-wave Doppler, proximal isovelocity surface area (flow-convergence), vena contracta or pulsed Doppler quantitative flow methods. ${ }^{18}$ Significant mitral valve stenosis was defined as an estimated mitral valve area of $2 \mathrm{~cm}^{2}$ or less, assessed using either the pressure half-time method or planimetry of the mitral orifice. Significant mitral valve disease was defined as more than mild mitral regurgitation or significant mitral valve stenosis.

\section{Follow-up and outcome measures}

Follow-up data were retrieved from health care databases, electronic medical records and death certificates. The outcomes were all-cause mortality and nonfatal ischemic stroke events. Ischemic stroke was defined as codes 433.x1, 434.x1 and 436 of the International Classification of Diseases, Ninth Revision (ICD-9). Patients who underwent cardiac transplantation during follow-up $(n=316)$ were censored at the time of the procedure.

\section{Statistical analysis}

Categorical variables were reported as percentages and comparison between groups based on the $\chi^{2}$ test. Continuous variables were reported as mean (SD) and differences were assessed using the unpaired $t$ test or by one-way analysis of variance (ANOVA), as appropriate. Cumulative event curves were estimated using the Kaplan-Meier method and compared using the log-rank test. We used Cox proportional hazards regression models to assess the associations between left atrial diameter and the outcomes. Hazard ratios (HRs) with 95\% confidence intervals (CIs) were estimated. The assumption of proportionality of hazards was verified using log-minus-log survival plots. Separate analyses were performed using left atrial diameter either as a continuous variable or categorized according to the sex-specific criteria of the American Society of Echocardiography. Multi- 
variable analyses were adjusted for the following covariables: age, sex, hypertension, diabetes, hypercholesterolemia, history of smoking, previous stroke or transient ischemic attack, history of atrial fibrillation, severity of mitral regurgitation, mitral valve stenosis, history of mitral valve intervention, history of congestive heart failure, prior myocardial infarction, history of coronary revascularization, left ventricular ejection fraction, end- diastolic left ventricular diameter, left ventricular mass, history of cancer, chronic kidney disease, chronic obstructive pulmonary disease, anticoagulant therapy, referral setting (i.e., admitted to hospital v. outpatient) and year of evaluation. The independent association of left atrial size with mortality was also verified among different subgroups according to age, sex, hypertension, history of atrial fibrillation, left ventricular ejection

Table 1: Baseline characteristics of study patients $(n=52639)$ by left atrial size

\begin{tabular}{|c|c|c|c|c|}
\hline \multirow[b]{2}{*}{ Characteristic } & \multicolumn{3}{|c|}{ No. $(\%)^{*}$} & \multirow[b]{2}{*}{$p$ value } \\
\hline & $\begin{array}{l}\text { All patients } \\
(n=52639)\end{array}$ & $\begin{array}{l}\text { Normal left atrium } \\
\quad(n=26540)\end{array}$ & $\begin{array}{l}\text { Enlarged left atrium } \\
\quad(n=26099)\end{array}$ & \\
\hline Sex, male & 27847 (52.9) & $13831(52.1)$ & $14016(53.7)$ & $<0.001$ \\
\hline Age, yr, mean (SD) & $61.8(16.3)$ & $56.8(17.8)$ & $66.9(12.7)$ & $<0.001$ \\
\hline Hypertension & $25416(48.3)$ & $10595(39.9)$ & $14821(56.8)$ & $<0.001$ \\
\hline Diabetes mellitus & $13369(25.4)$ & $5533(20.8)$ & $7836(30.0)$ & $<0.001$ \\
\hline Hypercholesterolemia & $24059(45.7)$ & $12125(45.7)$ & $11934(45.7)$ & $<0.001$ \\
\hline History of smoking & $12636(24.0)$ & $6033(22.7)$ & $6603(25.3)$ & $<0.001$ \\
\hline History of atrial fibrillation & $11250(21.4)$ & $2584 \quad(9.7)$ & $8666(33.2)$ & $<0.001$ \\
\hline History of stroke or TIA & $4904 \quad(9.3)$ & $2496 \quad(9.4)$ & $2408 \quad(9.2)$ & 0.48 \\
\hline Prior myocardial infarction & $4936 \quad(9.4)$ & $2044 \quad(7.7)$ & $2892(11.1)$ & $<0.001$ \\
\hline Coronary revascularization & 2465 (4.7) & $1051 \quad(4.0)$ & $1414 \quad(5.4)$ & $<0.001$ \\
\hline Percutaneous coronary intervention & 1564 & $757 \quad(2.9)$ & $807 \quad(3.1)$ & $<0.001$ \\
\hline Coronary artery bypass grafting & 1001 & $327 \quad(1.2)$ & $674(2.6)$ & $<0.001$ \\
\hline History of congestive heart failure & $6436(12.2)$ & $1559 \quad(5.9)$ & $4877(18.7)$ & $<0.001$ \\
\hline Moderate or severe MR & $2677 \quad(5.1)$ & 371 (1.4) & 2306 (8.8) & $<0.001$ \\
\hline MV stenosis & 836 (1.6) & $44 \quad(0.2)$ & $792(3.0)$ & $<0.001$ \\
\hline Valve prosthesis & $906 \quad(1.7)$ & $185 \quad(0.7)$ & $721 \quad(2.8)$ & $<0.001$ \\
\hline History of MV intervention & $454 \quad(0.9)$ & $30(0.1)$ & 424 (1.6) & $<0.001$ \\
\hline MV replacement or repair & $331 \quad(0.6)$ & $21(0.1)$ & $310(1.2)$ & $<0.001$ \\
\hline $\begin{array}{l}\text { Percutaneous or surgical MV } \\
\text { commisurotomy }\end{array}$ & $123(0.2)$ & $9(0.0)$ & $114(0.4)$ & $<0.001$ \\
\hline History of cancer & 3427 (6.5) & 1865 (7.0) & $1562(6.0)$ & $<0.001$ \\
\hline Chronic kidney disease & $13908(26.4)$ & $5583(21.0)$ & 8325 (31.9) & $<0.001$ \\
\hline Chronic obstructive pulmonary disease & $2968 \quad(5.6)$ & 1290 & $1678(6.4)$ & $<0.001$ \\
\hline Oral anticoagulant therapy & 3492 (6.6) & $758 \quad(2.9)$ & $2734(10.5)$ & $<0.001$ \\
\hline \multicolumn{5}{|l|}{ Referral pattern } \\
\hline Outpatient & $24226(46.0)$ & $12701(47.9)$ & $11525(44.2)$ & $<0.001$ \\
\hline Admitted to hospital & $28413(54.0)$ & $13839(52.1)$ & $14574(55.8)$ & $<0.001$ \\
\hline LVEF, \%, mean (SD) & $64.3(13.2)$ & $66.7(11.0)$ & $61.8(14.8)$ & $<0.001$ \\
\hline End-diastolic LV diameter, mm, mean (SD) & $48.3(7.6)$ & $46.5(6.3)$ & $50.0(8.3)$ & $<0.001$ \\
\hline End-systolic LV diameter, mm, mean (SD) & $31.1(8.4)$ & $29.0(6.4)$ & $33.1(9.6)$ & $<0.001$ \\
\hline LV enlargement & $5207 \quad(9.9)$ & 1062 (4.0) & 4145 (15.9) & $<0.001$ \\
\hline Ventricular septal thickness, mm, mean (SD) & $11.6(2.9)$ & $10.9(2.6)$ & $12.2(3.0)$ & $<0.001$ \\
\hline LV posterior wall thickness, mm, mean (SD) & $10.7(2.2)$ & $10.1(2.1)$ & 11.2 & $<0.001$ \\
\hline LV mass, g, mean (SD) & $205.8(82.1)$ & $177.6(65.8)$ & $233.5(87.1)$ & $<0.001$ \\
\hline
\end{tabular}


fraction, left ventricular enlargement, severity of mitral regurgitation and year of evaluation. For these subgroup analyses, the corresponding variable related to the subgroups was removed from the list of adjusting variables.

\section{Results}

\section{Clinical and echocardiographic characteristics}

The mean age of patients was 61.8 (SD 16.3) years, and 27847 of them (52.9\%) were men. The demographic and clinical characteristics of the 52639 patients are summarized in Table 1.

The main reasons for performing the echocardiograms included dyspnea or heart failure in 8382 patients $(15.9 \%)$, heart murmur in 7609 patients $(14.5 \%)$, palpitations or arrhythmia (including atrial fibrillation) in 10743 patients (20.4\%), search for a cardiac source of embolism in 3540 patients (6.7\%), syncope or presyncope in 1962 patients (3.7\%), suspected or confirmed endocarditis in 1477 patients $(2.8 \%)$, chest pain in 1600 patients (3\%), evaluation of known valvular heart disease in 2658 patients (5\%), assessment of left ventricular wall thickness in 1858 patients (3.5\%),

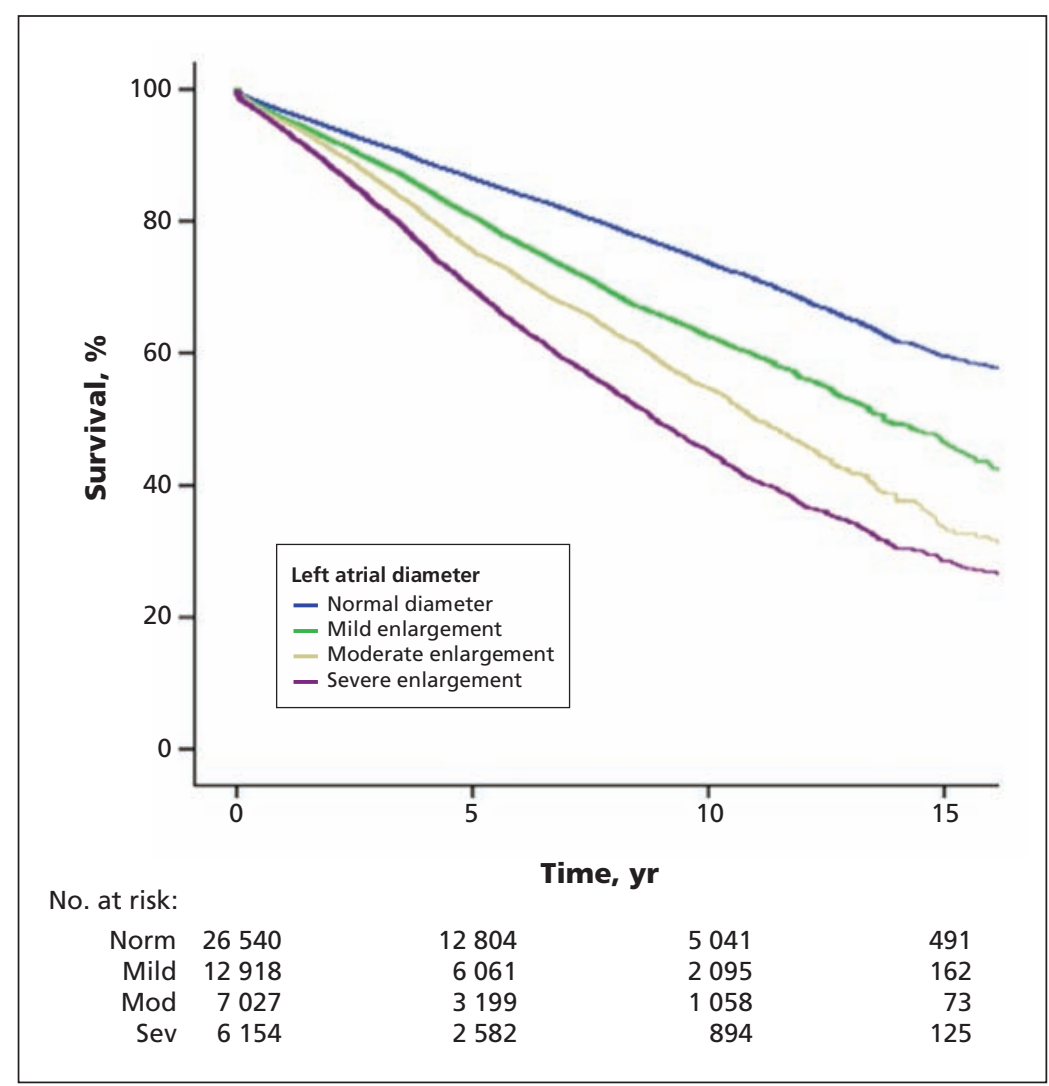

Figure 1: Kaplan-Meier survival curves stratified according to left atrial diameter $(p<0.001)$. Normal = left atrial diameter $<4.1 \mathrm{~cm}$ in men or $<3.9 \mathrm{~cm}$ in women; mild enlargement $=4.1-4.6 \mathrm{~cm}$ in men or $3.9-4.2 \mathrm{~cm}$ in women; moderate enlargement $=4.7-5.1 \mathrm{~cm}$ in men or $4.3-4.6 \mathrm{~cm}$ in women; severe enlargement $=\geq 5.2 \mathrm{~cm}$ in men or $\geq 4.7 \mathrm{~cm}$ in women. electrocardiographic abnormalities (other than rhythm disorders or left ventricular hypertrophy) in 1933 patients $(3.7 \%)$, suspected or confirmed pericardial disease in 864 patients $(1.6 \%)$ and suspected cardiomegaly in 821 patients $(1.6 \%)$.

The mean left atrial diameter was 4.03 (SD 0.77$) \mathrm{cm}$. According to the criteria of the American Society of Echocardiography, left atrial diameter was normal in 26540 patients (50.4\%), mildly enlarged in 12918 patients $(24.5 \%)$, moderately enlarged in 7027 patients $(13.3 \%)$ and severely enlarged in 6154 patients (11.7\%).

Patients with left atrial enlargement were older and were more likely to have a history of hypertension, diabetes and atrial fibrillation. Left atrial enlargement was also associated with lower left ventricular ejection fraction and higher left ventricular dimensions and mass (Table 1).

\section{Left atrial size and outcome}

During a mean follow-up of 5.5 (SD 4.1, interquartile range 2.1-8.6) years, a total of 12527 patients died, and 2314 patients had at least one nonfatal ischemic stroke event. The crude cumulative 10 -year survival was $73.7 \%$ among patients with normal left atrial size, $62.5 \%$ among those with mild left atrial enlargement, 54.8\% among those with moderate left atrial enlargement and $45 \%$ among those with severe left atrial enlargement $(p<0.001)$ (Figure 1). This graded association between left atrial size and mortality was consistent in several clinically relevant subgroups, including those stratified according to sex, age, hypertension, history of atrial fibrillation, left ventricular systolic function and left ventricular enlargement (Appendix 1, available at www.cmaj .ca/lookup/suppl/doi:10.1503/cmaj.091688/-/DC).

In univariable analysis, left atrial diameter was significantly associated with time to death (HR per $1-\mathrm{cm}$ increment $1.61,95 \%$ CI $1.57-1.66$, $p<0.001$ in women, and HR 1.43, 95\% CI 1.39$1.47, p<0.001$ in men). After covariable adjustment, left atrial diameter remained an independent predictor of mortality either when included as a continuous variable (adjusted HR per $1-\mathrm{cm}$ increment 1.17 , 95\% CI 1.12-1.22, $p<0.001$ in women, and HR 1.09, 95\% CI 1.05-1.13, $p<0.001$ in men) or as a sex-specific binary variable (HR 1.10, 95\% CI 1.06-1.14, $p<0.001$ ). Table 2 shows the association of left atrial size with all-cause mortality in the whole population by severity of left atrial enlargement, based on the criteria the American Society of Echocardiography and stratified according to sex.

The association of left atrial enlargement with mortality was also consistent in strata of several subgroups, including age, hypertension, atrial fib- 
Table 2: Crude and multivariable adjusted hazard ratios for all-cause mortality by the degree of left atrial enlargement in the whole population and stratified according to sex

Left atrial diameter

\begin{tabular}{|c|c|c|c|c|}
\hline \multirow[b]{2}{*}{ Group } & \\
\hline & Normal & Mildly enlarged & Moderately enlarged & Severely enlarged \\
\hline \multicolumn{5}{|l|}{ All patients } \\
\hline Deaths/patients & $4657 / 26540$ & $3248 / 12918$ & $2221 / 7027$ & $2401 / 6154$ \\
\hline Crude HR $(95 \% \mathrm{Cl})$ & 1.00 & $1.50(1.44-1.57)$ & $1.94(1.84-2.04)$ & $2.49(2.37-2.62)$ \\
\hline Multivariable adjusted $\mathrm{HR}^{*}(95 \% \mathrm{Cl})$ & 1.00 & $1.02(0.97-1.07)$ & $1.12(1.06-1.18)$ & $1.37(1.29-1.45)$ \\
\hline \multicolumn{5}{|l|}{ Women } \\
\hline Deaths/patients & $1768 / 12709$ & $1121 / 5060$ & $970 / 3317$ & $1432 / 3706$ \\
\hline Crude HR $(95 \% \mathrm{Cl})$ & 1.00 & $1.65(1.53-1.78)$ & $2.21(2.05-2.39)$ & $3.03(2.83-3.25)$ \\
\hline Multivariable adjusted $\mathrm{HR}^{*}(95 \% \mathrm{Cl})$ & 1.00 & $1.10(1.02-1.19)$ & $1.20(1.10-1.30)$ & $1.41(1.30-1.54)$ \\
\hline \multicolumn{5}{|l|}{ Men } \\
\hline Deaths/patients & $2889 / 13831$ & $2127 / 7858$ & $1251 / 3710$ & $969 / 2448$ \\
\hline Crude HR $(95 \% \mathrm{Cl})$ & 1.00 & $1.36(1.29-1.44)$ & $1.77(1.66-1.89)$ & $2.26(2.10-2.43)$ \\
\hline Multivariable adjusted $\mathrm{HR}^{*}(95 \% \mathrm{Cl})$ & 1.00 & $0.97(0.92-1.03)$ & $1.06(0.99-1.14)$ & $1.29(1.18-1.40)$ \\
\hline \multicolumn{5}{|c|}{$\begin{array}{l}\text { Note: } \mathrm{Cl}=\text { confidence interval, } \mathrm{HR}=\text { hazard ratio. } \\
\text { *Adjusted for age, sex, hypertension, diabetes, hypercholesterolemia, history of smoking, previous stroke or transient ischemic attack, history of atrial fibrillation, } \\
\text { severity of mitral regurgitation, mitral valve stenosis, history of mitral valve intervention, history of congestive heart failure, prior myocardial infarction, history of } \\
\text { coronary revascularization, left ventricular ejection fraction, end-diastolic left ventricular diameter, left ventricular mass, history of cancer, chronic kidney disease, } \\
\text { chronic obstructive pulmonary disease, anticoagulant therapy, referral setting (i.e., admitted to hospital v. outpatient) and year of evaluation. }\end{array}$} \\
\hline
\end{tabular}

Table 3: Prognostic value of left atrial size* in adjusted multivariable models for the prediction of mortality across a range of baseline characteristics

\begin{tabular}{|c|c|c|c|c|}
\hline \multirow[b]{2}{*}{ Variable } & \multirow[b]{2}{*}{$\begin{array}{l}\text { Normal left } \\
\text { atrial size }\end{array}$} & \multicolumn{3}{|c|}{ Hazard ratio ( $95 \%$ confidence interval) } \\
\hline & & $\begin{array}{l}\text { Mild left atrial } \\
\text { enlargement }\end{array}$ & $\begin{array}{l}\text { Moderate left atrial } \\
\text { enlargement }\end{array}$ & $\begin{array}{l}\text { Severe left atrial } \\
\text { enlargement }\end{array}$ \\
\hline Age $<60 y$ & 1.00 & $1.35(1.20-1.51)$ & $1.62(1.38-1.89)$ & $1.97(1.64-2.37)$ \\
\hline Age $\geq 60 y$ & 1.00 & $1.06(1.01-1.11)$ & $1.16(1.09-1.22)$ & $1.45(1.37-1.55)$ \\
\hline No history of hypertension & 1.00 & $1.05(0.98-1.12)$ & $1.11(1.02-1.21)$ & $1.41(1.29-1.55)$ \\
\hline Hypertension & 1.00 & $1.00(0.94-1.07)$ & $1.14(1.06-1.23)$ & $1.35(1.25-1.46)$ \\
\hline No history of AF & 1.00 & $1.03(0.98-1.08)$ & $1.17(1.10-1.25)$ & $1.34(1.24-1.45)$ \\
\hline Prior history of AF & 1.00 & $0.99(0.90-1.10)$ & $1.02(0.92-1.13)$ & $1.32(1.20-1.46)$ \\
\hline LVEF $<55 \%$ & 1.00 & $0.99(0.91-1.09)$ & $1.12(1.02-1.24)$ & $1.26(1.14-1.40)$ \\
\hline LVEF $\geq 55 \%$ & 1.00 & $1.03(0.97-1.08)$ & $1.10(1.03-1.18)$ & $1.40(1.30-1.50)$ \\
\hline Normal LV size & 1.00 & $1.00(0.95-1.05)$ & $1.07(1.01-1.14)$ & $1.29(1.21-1.38)$ \\
\hline LV enlargement & 1.00 & $1.11(0.96-1.30)$ & $1.31(1.13-1.52)$ & $1.55(1.33-1.80)$ \\
\hline No or mild MR & 1.00 & $1.03(0.98-1.07)$ & $1.13(1.07-1.19)$ & 1.35 (1.27-1.44) \\
\hline Moderate or severe MR & 1.00 & $0.94(0.73-1.20)$ & $1.09(0.86-1.38)$ & $1.41(1.13-1.76)$ \\
\hline Year of evaluation 1990-1999 & 1.00 & $1.06(0.99-1.13)$ & $1.17(1.09-1.26)$ & $1.45(1.34-1.57)$ \\
\hline Year of evaluation $2000-2008$ & 1.00 & $0.99(0.92-1.05)$ & $1.08(1.00-1.17)$ & $1.32(1.21-1.44)$ \\
\hline $\begin{array}{l}\text { No history of significant MV } \\
\text { disease, MV intervention or AF }\end{array}$ & 1.00 & $1.03(0.98-1.09)$ & $1.18(1.10-1.26)$ & $1.33(1.22-1.45)$ \\
\hline \multicolumn{5}{|c|}{$\begin{array}{l}\text { AF = atrial fibrillation, } L V=\text { left ventricular, } L V E F=\text { left ventricular ejection fraction, } M V=\text { mitral valve, MR = mitral regurgitation. } \\
\text { *According to the sex-specific criteria of the American Society of Echocardiography. } \\
\text { tAdjusted for age, sex, hypertension, diabetes, hypercholesterolemia, history of smoking, previous stroke or transient ischemic attack, history of atrial fibrillation, } \\
\text { severity of mitral regurgitation, mitral valve stenosis, history of mitral valve intervention, history of congestive heart failure, prior myocardial infarction, history o } \\
\text { coronary revascularization, left ventricular ejection fraction, end-diastolic left ventricular diameter, left ventricular mass, history of cancer, chronic kidney disease, } \\
\text { chronic obstructive pulmonary disease, anticoagulant therapy, referral setting (i.e., admitted to hospital v. outpatient) and year of evaluation. }\end{array}$} \\
\hline
\end{tabular}


rillation, left ventricular ejection fraction, left ventricular enlargement, mitral regurgitation severity and year of evaluation (Table 3 ). This association remained significant even when patients with a history of atrial fibrillation, significant mitral valve disease or mitral valve intervention were excluded (Table 3). However, there was evidence of some effect modification. In particular, there was evidence of interaction between left atrial size and left ventricular size, such that the adjusted HRs for all-cause mortality were higher among patients with left ventricular enlargement (HR per 1-cm increment 1.22, 95\% CI $1.10-1.34, p<0.001$ in women, and HR 1.29, 95\% CI $1.19-1.41, p<0.001$ in men) than in those with normal left ventricular size (HR 1.17, 95\% CI 1.11-1.22, $p<0.001$ in women, and HR $1.04,95 \%$ CI 1.00-1.08, $p=0.07$ in men).

The cumulative 10-year rate of nonfatal ischemic stroke events was $5.4 \%$ among patients with normal left atrial size, $9.1 \%$ among those with mild enlargement, $10.1 \%$ among those with moderate enlargement and $11.9 \%$ among those with severe enlargement $(p<0.001$, Figure 2$)$. After multivariable adjustment, the association of left atrial diameter with ischemic stroke

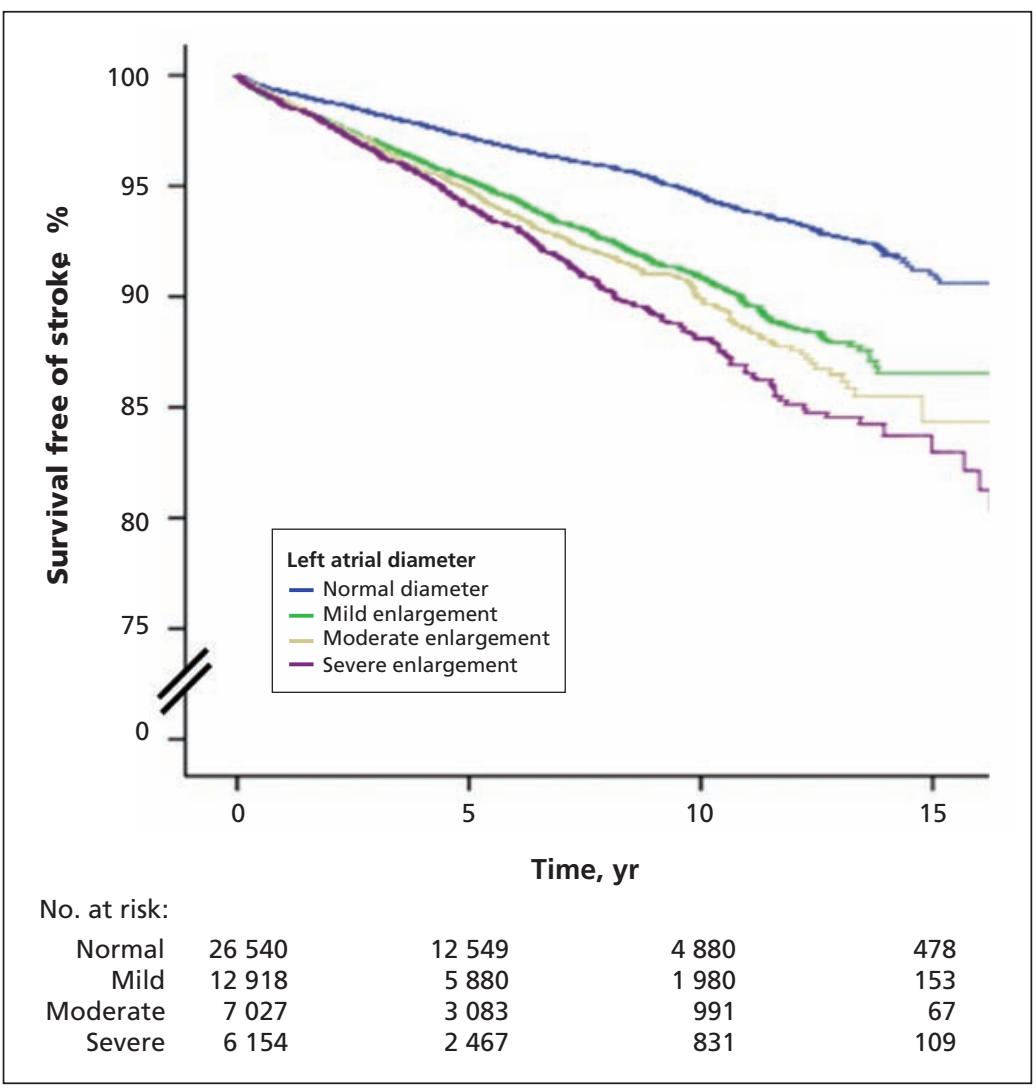

Figure 2: Survival free of stroke according to left atrial size $(p<0.001)$. Normal $=$ left atrial diameter $<4.1 \mathrm{~cm}$ in men or $<3.9 \mathrm{~cm}$ in women; mild enlargement $=4.1-4.6 \mathrm{~cm}$ in men or $3.9-4.2 \mathrm{~cm}$ in women; moderate enlargement $=4.7-$ $5.1 \mathrm{~cm}$ in men or $4.3-4.6 \mathrm{~cm}$ in women; severe enlargement $=\geq 5.2 \mathrm{~cm}$ in men or $\geq 4.7 \mathrm{~cm}$ in women. remained significant among women (HR per 1 -cm increment $1.25,95 \%$ CI $1.14-1.37$, $p<0.001$ ) but not among men (HR 0.96, 95\% CI $0.88-1.06, p=0.43$ ). When left atrial size was categorized for women according to the criteria of the American Society of Echocardiography and normal left atrial size was used as the reference category, there was also a graded and significant association with ischemic stroke (adjusted HR for mild left atrial enlargement $1.24,95 \%$ CI $1.05-1.46, p=0.01$, HR for moderate left atrial enlargement 1.32 , 95\% CI 1.10 $1.59, p=0.003$, and HR for severe left atrial enlargement $1.59,95 \%$ CI $1.32-1.91, p<0.001$ ).

\section{Interpretation}

Our study shows that, in a large population of patients referred for transthoracic echocardiography, left atrial size has a graded and independent association with all-cause mortality in both sexes and with ischemic stroke in women.

A number of population-based studies have assessed the value of left atrial size for predicting mortality and cardiovascular events. Benjamin and colleagues ${ }^{9}$ evaluated 3099 patients age 50 years and older, and found that left atrial diameter was a predictor of death in both sexes. Nagarajarao and coauthors ${ }^{12}$ reported that left atrial size was a predictor of mortality in African Americans, but the relation of left atrial diameter with stroke was not significant after adjustment for left ventricular hypertrophy and left ventricular ejection fraction. Kizer and coworkers ${ }^{19}$ found that left atrial diameter was a predictor of fatal and nonfatal cardiovascular events in a population of 2804 American Indians. Laukkanen and colleagues ${ }^{11}$ found that left atrial diameter was associated with cardiovascular death; however, this association did not remain significant after adjustment for left ventricular mass. The association between left atrial diameter and all-cause mortality in multivariable analysis was not significant either. ${ }^{11}$ Finally, Benjamin and coauthors, ${ }^{9}$ and Di Tullio and coworkers,$^{20}$ reported that left atrial size was a predictor of ischemic stroke in men, but not in women, which contrasts with our results; differences in the characteristics of the patients included might explain at least part of these discrepancies.

We assessed the value of left atrial size for predicting outcome in patients referred for clinical reasons. This allowed us to investigate the association of left atrial size and outcome in a wide range of clinically relevant subgroups. Our results complement and expand previous observations on the value of left atrial size for predict- 
ing outcome in patients with left ventricular systolic dysfunction, ${ }^{21-23}$ patients with myocardial infarction, ${ }^{24,25}$ patients with known or suspected coronary artery disease referred for stress echocardiography, ${ }^{26,27}$ and patients with hypertrophic cardiomyopathy. ${ }^{28}$

The mechanisms accounting for the association of left atrial size with outcome have not been fully unraveled. Left atrial enlargement may predispose to atrial fibrillation, ${ }^{6}$ which in turn may increase the risk of embolic events, heart failure and death. ${ }^{29}$ On the other hand, left atrial dilation may be a marker of the severity of other risk factors for cardiovascular events, such as hypertension, ${ }^{30}$ left ventricular diastolic dysfunction $^{31}$ or mitral valve disease. ${ }^{32}$ These conditions may lead to left atrial pressure or volume overload which, if chronically maintained, may result in left atrial remodeling and enlargement. ${ }^{2}$ In fact, left atrial size may reflect more accurately the duration and severity of chronic elevations in left ventricular filling pressures than Doppler parameters of diastolic function. ${ }^{3,33}$ While the latter may be readily altered by transient changes in loading conditions, left atrial size may better reflect the cumulative effect of left ventricular filling pressure over time.

\section{Limitations}

Our study has several limitations. Even though we controlled for several important covariables, because this was an observational study, residual confounding may account for at least part of the observed differences in outcome. We did not account for a number of variables which might be related to outcome, such as body mass index, antihypertensive medications or Doppler estimators of left ventricular diastolic function. On the other hand, left atrial diameter was evaluated by either M-mode or two-dimensional echocardiography; although the linear distance measured by both methods is theoretically the same, some discrepancies may occur. Finally, left atrial volume is a more reliable estimator of left atrial size than left atrial diameter, ${ }^{34}$ and also may be a more accurate predictor of cardiovascular events; ${ }^{35}$ however, left atrial diameter is more readily available and more widely employed in clinical practice.

\section{Conclusion}

Left atrial diameter has a graded and independent association with all-cause mortality in both sexes and with ischemic stroke in women. Further research is warranted to refine the prognostic utility of this simple echocardiographic parameter and to determine the degree to which other indices of left atrial size, such as left atrial volume, may improve this prognostic information.

\section{References}

1. Abhayaratna WP, Seward JB, Appleton CP, et al. Left atrial size: physiologic determinants and clinical applications. $J$ Am Coll Cardiol 2006;47:2357-63.

2. Leung DY, Boyd A, Ng AA, et al. Echocardiographic evaluation of left atrial size and function: current understanding, pathophysiologic correlates, and prognostic implications. Am Heart $J$ 2008; 156:1056-64.

3. Douglas PS. The left atrium: a biomarker of chronic diastolic dysfunction and cardiovascular disease risk. J Am Coll Cardiol 2003;42:1206-7

4. Flaker GC, Fletcher KA, Rothbart RM, et al. Clinical and echocardiographic features of intermittent atrial fibrillation that predict recurrent atrial fibrillation. Stroke Prevention in Atrial Fibrillation (SPAF) Investigators. Am J Cardiol 1995;76:355-8.

5. Tsang TS, Barnes ME, Bailey KR, et al. Left atrial volume: important risk marker of incident atrial fibrillation in 1655 older men and women. Mayo Clin Proc 2001;76:467-75.

6. Vaziri SM, Larson MG, Benjamin EJ, et al. Echocardiographic predictors of nonrheumatic atrial fibrillation. The Framingham Heart Study. Circulation 1994;89:724-30.

7. Psaty BM, Manolio TA, Kuller LH, et al. Incidence of and risk factors for atrial fibrillation in older adults. Circulation 1997;96: 2455-61.

8. Barnes ME, Miyasaka Y, Seward JB, et al. Left atrial volume in the prediction of first ischemic stroke in an elderly cohort without atrial fibrillation. Mayo Clin Proc 2004;79:1008-14.

9. Benjamin EJ, D'Agostino RB, Belanger AJ, et al. Left atrial size and the risk of stroke and death. The Framingham Heart Study. Circulation 1995;92:835-41.

10. Gardin JM, McClelland R, Kitzman D, et al. M-mode echocardiographic predictors of six- to seven-year incidence of coronary heart disease, stroke, congestive heart failure, and mortality in an elderly cohort (the Cardiovascular Health Study). Am J Cardiol 2001;87:1051-7.

11. Laukkanen JA, Kurl S, Eranen J, et al. Left atrium size and the risk of cardiovascular death in middle-aged men. Arch Intern Med 2005; 165:1788-93.

12. Nagarajarao HS, Penman AD, Taylor HA, et al. The predictive value of left atrial size for incident ischemic stroke and all-cause mortality in African Americans: the Atherosclerosis Risk in Communities (ARIC) Study. Stroke 2008;39:2701-6.

13. Tsang TS, Barnes ME, Gersh BJ, et al. Prediction of risk for first age-related cardiovascular events in an elderly population: the incremental value of echocardiography. J Am Coll Cardiol 2003; 42:1199-205.

14. Levey AS. Nondiabetic kidney disease. N Engl J Med. 2002;347: 1505-11.

15. Sahn DJ, DeMaria A, Kisslo J, et al. Recommendations regarding quantitation in M-mode echocardiography: results of a survey of echocardiographic measurements. Circulation 1978;58:1072-83.

16. Lang RM, Bierig M, Devereux RB, et al. Recommendations for chamber quantification: a report from the American Society of Echocardiography's Guidelines and Standards Committee and the Chamber Quantification Writing Group, developed in conjunction with the European Association of Echocardiography, a branch of the European Society of Cardiology. J Am Soc Echocardiogr 2005; 18:1440-63.

17. Devereux RB, Alonso DR, Lutas EM, et al. Echocardiographic assessment of left ventricular hypertrophy: comparison to necropsy findings. Am J Cardiol 1986;57:450-8.

18. Zoghbi WA, Enriquez-Sarano M, Foster E, et al. Recommendations for evaluation of the severity of native valvular regurgitation with two-dimensional and Doppler echocardiography. J Am Soc Echocardiogr 2003; 16:777-802.

19. Kizer JR, Bella JN, Palmieri V, et al. Left atrial diameter as an independent predictor of first clinical cardiovascular events in middle-aged and elderly adults: the Strong Heart Study (SHS). Am Heart J 2006;151:412-8.

20. Di Tullio MR, Sacco RL, Sciacca RR, et al. Left atrial size and the risk of ischemic stroke in an ethnically mixed population. Stroke 1999;30:2019-24.

21. Dini FL, Cortigiani L, Baldini U, et al. Prognostic value of left atrial enlargement in patients with idiopathic dilated cardiomyopathy and ischemic cardiomyopathy. Am J Cardiol 2002;89: 518-23.

22. Rossi A, Cicoira M, Zanolla L, et al. Determinants and prognostic value of left atrial volume in patients with dilated cardiomyopathy. J Am Coll Cardiol 2002;40:1425-30. 
23. Sabharwal N, Cemin R, Rajan K, et al. Usefulness of left atrial volume as a predictor of mortality in patients with ischemic cardiomyopathy. Am J Cardiol 2004;94:760-3.

24. Moller JE, Hillis GS, Oh JK, et al. Left atrial volume: a powerful predictor of survival after acute myocardial infarction. Circulation 2003;107:2207-12.

25. Beinart R, Boyko V, Schwammenthal E, et al. Long-term prognostic significance of left atrial volume in acute myocardial infarction. J Am Coll Cardiol 2004;44:327-34.

26. Bangalore S, Yao SS, Chaudhry FA. Role of left atrial size in risk stratification and prognosis of patients undergoing stress echocardiography. J Am Coll Cardiol 2007;50:1254-62.

27. Tsutsui JM, Dourado PM, Elhendy A, et al. Prognostic value of left atrial volume in patients who underwent dobutamine stress echocardiography for known or suspected coronary artery disease. Am Heart J 2008;156:1110-6.

28. Nistri S, Olivotto I, Betocchi S, et al. Prognostic significance of left atrial size in patients with hypertrophic cardiomyopathy (from the Italian Registry for Hypertrophic Cardiomyopathy). Am J Cardiol 2006;98:960-5.

29. Benjamin EJ, Wolf PA, D'Agostino RB, et al. Impact of atria fibrillation on the risk of death: the Framingham Heart Study. Circulation 1998;98:946-52.

30. Vaziri SM, Larson MG, Lauer MS, et al. Influence of blood pressure on left atrial size. The Framingham Heart Study. Hypertension 1995;25:1155-60.

31. Pritchett AM, Mahoney DW, Jacobsen SJ, et al. Diastolic dysfunction and left atrial volume: a population-based study. J Am Coll Cardiol 2005;45:87-92.

32. Messika-Zeitoun D, Bellamy M, Avierinos JF, et al. Left atria remodelling in mitral regurgitation-methodologic approach, physiological determinants, and outcome implications: a prospective quantitative Doppler-echocardiographic and electron beamcomputed tomographic study. Eur Heart J 2007;28:1773-81.

33. Tsang TS, Barnes ME, Gersh BJ, et al. Left atrial volume as a morphophysiologic expression of left ventricular diastolic dys- function and relation to cardiovascular risk burden. Am J Cardiol 2002;90:1284-9.

34. Lester SJ, Ryan EW, Schiller NB, et al. Best method in clinical practice and in research studies to determine left atrial size. Am J Cardiol 1999;84:829-32.

35. Tsang TS, Abhayaratna WP, Barnes ME, et al. Prediction of cardiovascular outcomes with left atrial size: is volume superior to area or diameter? J Am Coll Cardiol 2006;47:1018-23.

Affiliations: From the Department of Cardiology (BouzasMosquera, Álvarez-García, Méndez, Peteiro, Prada, CastroBeiras), Hospital Universitario A Coruña, A Coruña, Spain; the Spanish Cooperative Cardiovascular Disease Research Network (RECAVA) (Bouzas-Mosquera, Peteiro, CastroBeiras), Instituto de Salud Carlos III, Madrid, Spain; the Department of Information Technology (Broullón), Hospital Universitario A Coruña, A Coruña, Spain; Servicio Galego de Saúde (Gándara-Sambade), A Coruña, Spain; and the Department of Cardiac Surgery (Mosquera), Hospital Universitario A Coruña, A Coruña, Spain.

Contributors: Alberto Bouzas-Mosquera, Francisco Broullón and Nemesio Álvarez-García were responsible for the conception and design of the study. Alberto Bouzas-Mosquera and Teresa Gándara-Sambade performed the statistical analysis. Alberto Bouzas-Mosquera, Francisco Broullón, Nemesio Álvarez-García, Elizabet Méndez, Jesús Peteiro, Oscar Prada and Victor Mosquera acquired the data. Alberto Bouzas-Mosquera and Francisco Broullón drafted the manuscript. Nemesio Álvarez-García and Alfonso Castro-Beiras supervised the study. All of the authors critically revised the manuscript for important intellectual content and approved the final version submitted for publication. 